\title{
Seismic Reinforcement of Existing Masonry Structure On Conceptual Design
}

\author{
Hongwei $\mathrm{Qi}^{1}{ }^{1} *$, Xiaoning Huang ${ }^{2}$ \\ ${ }^{I}$ Department of Civil Engineering, North China Institute of Science and Technology, Beijing, 101601, China \\ ${ }^{2}$ Department of Civil Engineering, Lanzhou University of Technology, Lanzhou, 730050, China
}

\begin{abstract}
In this paper, earthquake-resistance behaviors of existing masonry structures are evaluated based on a certain masonry building. The existing masonry structure is evaluated in its defects of primary design and construction measurements, seismic bearing capacity and durability. Based on results of evaluation, the seismic reinforcement design is introduced for improving earthquake-resistance behaviors of the whole building and its weak positions. In the seismic reinforcement concept design, the ductility of the masonry structure is improved in bearing seismic loading and plastic deformation. Further more, the masonry building is reinforced for avoiding collapse due to the weak positions of its bottom and top layers, stair halls, short walls and wall corners. Evaluation results and the corresponding seismic reinforcement design are significant for safety of both existing and newly designed masonry structures in earth-quake areas.
\end{abstract}

Keywords: Seismic reinforcement, masonry structure, conceptual design.

\section{INTRODUCTION}

Masonry structure has been very common in multi-story building construction for 30 years in Chinese cities. Traditionally, it uses fired common brick and mortar mix to build the wall. The interior and exterior bricks are integrally connected together by racking bond. The materials and the constructing way make the whole structure very brittle, which is the key element to explain why the traditional masonry structure easy to be destroyed in severe earthquakes.

The masonry structure of existing buildings in chinese is changing with the time, as the seismic fortification criterion and construction quality is different at different time. Different structural forms bear different seismic capability. Before 1980, earthquake fortification was hardly taken into consideration. Luckily, most of the buildings constructed at that time have been demolished by now. Then, some seismic measures were required in 1980 s, but the fortification criterion is still very low. So the buildings constructed at that time normally bear very weak earthquake-resistant strength. It is not until 1990s that masonry buildings bear much better seismic capability due to sensible structure design and better construction quality.

In Wenchuan earthquake, the damage of masonry building was the most serious of all buildings, many masonry buildings were badly damaged, even collapsed. In medium and small cities in china, a certain amount of masonry buildings exist safety potential. Expert suggests [1] analytical re-

\footnotetext{
*Address correspondence to this author at the Department of Civil Engineering, North China Institute of Science and Technology, Beijing 101601, China; Tel: +86-010-61594887(office), +86-13930645986 (Mobile); Fax: +86-010-61594887;

E-mails: qihongwei@ncist.edu.cn, hwhao2008@126.com
}

design to the buildings with safety potentials. We should never take any chance, but try our best to delete the hidden dangers and strengthen the seismic bearing capability whenever possible. Seismic reinforcement can strengthen the safety of the building, prolong its life, decrease the damage and collapse in severe and strong earthquakes, so as to protect human life and property.

\section{ANALYSIS OF INSECTURITY ELEMENTS OF EX- ISTING MASONRY STRUCTURE}

In Wenchuan earthquake, a lots of masonry structure were destroyed, and those damage phenomena were popular $[1,2]$. The weak positions in structural arrangement are firstly damaged, including vertical weakened layers, horizontal concave and convex parts and joints. The crossing diagonal cracks are frequently seen on the wall between windows, cracks will extend quickly when there is no structural concrete column and ring beam to bind, and cause collapse or progressive collapse of the building. Short wall structures are seriously damaged, featured with unidirectional shear diagonal cracks, vertical cracks and horizontal cracks, etc. Wall corners are seriously damaged with serious cracks or even collapsed.

In 1980s and initial years in 1990s, the design of masonry structure in china has those characteristic: structure form was regular, the distance between the cross walls was small, and the precast slabs used popular. Although some seismic measures were designed, but the fortification criterion was very low, the details of seismic design were not very well. Those inspects hereinafter were show in design: structural concrete column and ring beam set deficient and had little effect on structure, the quality of many precast slabs were poor, especially the cold-finished steels were once largely used in slabs, the cold-finished steels have weak ductility and break easily. Those building have used twenty or thirty 
years, decorated and reconstructed several times, the durability of structure was generally reduced.

\section{SEISMIC REINFORCEMENT CONCEPT DESIGN FOR MASONRY STRUCTURE}

To increase the seismic bearing capability of the massive structure. The basic principles of reinforcement design for masonry structure [2] are to strengthen the integrity of the massive structure, to improve the bearing capability of local parts, so as to increase the comprehensive seismic bearing capability of the whole structure. After reinforcement, the classification of the building's earthquake fortification, the correspondent measures for earthquake resistance and the checking requirements for seismic fortification should all be measured by the current Standards for Seismic Appraiser of Building. The three earthquake performance objectives [3, 4] are to "stay still in small earthquake, stay stable in middle earthquake and stay up in big earthquake". The design proposal for structure reinforcement should lay emphasis on the stability of the whole structure, which rests with the detailed analysis and optimal design of the structure, trans-force approach and structural connection.

To analyze the seismic bearing capability of the key parts. The earthquake in Wenchuan has shown that both the bottom and top layers of masonry structure tend to be badly damaged [5-7], so do some local parts, such as wall corners, short walls, and stair halls. Those damages often lead to subsequent structural collapse.

According to the current masonry structure design criterion, when masonry structure is under an appropriate proportion of height and width, we just need to check its earthquake-resistant strength under horizontal seismic actions and we'd better apply to the equivalent base shear method in the design. The designer should lay special attention on the shear resistance of both cross wall and longitudinal wall on their own planes under the effect of horizontal seismic actions along the cross and vertical axis of the building. The story shear force is distributed according to the ratio of lateral re- sistance of every wall to its own stiffness on the same story. According to the calculation results of equivalent base shear method, the bottom layer of masonry structure suffers the biggest seismic shear, while the top layer the shortest; the wall with high rigidity suffers more, while the short wall with low rigidity suffers less. However, the space force resistance property of the wall around stair hall and between windows are normally not taken into consideration, so that in calculation the seismic bearing capability of the top layer, short walls, and wall in stair halls tend to be very high. Therefore, those parts are often neglected by designers. This paper will lay some special attention on them in the reinforcement design.

\section{ANALYSIS OF AN EXISTING MASONRY BUILDING}

The example to be reinforced is a six-story masonry structure built in 1989 for residential use, with each story 2.9 $\mathrm{m}$ high. It is the cross wall to bear the load. The structural concrete columns are set at the wall corners of each unit and also the four corners of stair hall. Ring beam is set at every floor. All the other room floors use precast concrete slabs, while the bathroom and the kitchen use casting floor slabs. The load bearing wall is built with MU10 clay bricks and M7.5 composite mortar. The plain layout of the building is as in Fig. (1).

The building is currently in very good condition, there is no uneven settlement in the massive structure and no permanent damage in the major structure, but most of the apartments have been decorated and revamped, which makes the material load heavier.

The building's seismic fortification intensity is set for 7 , its designed life expectancy is 50 years long. According to the design principle of equivalent base shear method, the bottom parts of the structure suffer the strongest force, so that their seismic bearing capability is the weakest. The exterior vertical walls between windows from $1^{\text {st }}$ to $3^{\text {rd }}$ floor, the rigid interior vertical walls and the gable walls all can not meet the requirement for seismic resistance, indivial walls

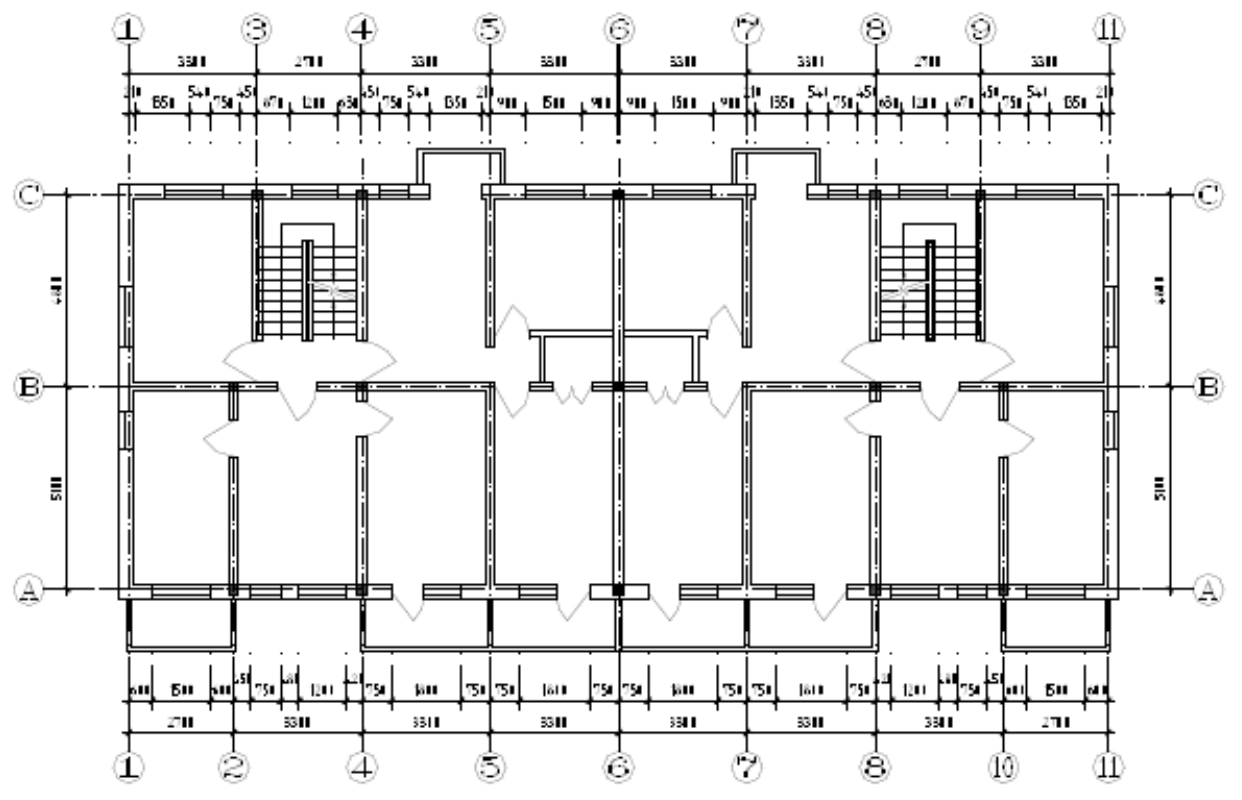

Fig. (1). Architectural Plan. 
from $4^{\text {th }}$ to $5^{\text {th }}$ floor can not meet the requirement too.but the seismic resistance of the top layer and the short walls are very high. Table 1 shows the seismic calculation results of main walls.

There are several structural shortcomings in this design. The size of structural concrete column is $240 \mathrm{~mm} * 240 \mathrm{~mm}$. This column does not produce strong enough constraint force to the wall. The longitudinal steel in the column is $4 \Phi 10$, the stirrup is 66@250, and is not densely laid at node parts. And the size of ring beam is $180 \mathrm{~mm}^{*} 150 \mathrm{~mm}$. The longitudinal steel and the stirrup in ring beam are completely in the same modal as in the column. Apparently, both the structural concrete column and the ring beam do not meet the current seismic fortification requirements against 8 seismic fortification intensity. The shortest wall, 1000mmin length, is the part from the edge of exterior load bearing wall to that of the window hole, which is shorter than the required standard local wall size, $1200 \mathrm{~mm}$ in length. Besides, there are many short walls without cross walls to support on both the interior and exterior horizontal walls.

\section{PROPOSAL FOR SEISMIC OVERALL REIN- FORCEMENT}

The seismic fortification intensity is set for 8; the basic acceleration of ground motion is set for $0.2 \mathrm{~g}$; the supposed earthquake is in Group 1.

Considering the practicability to strengthen the massive structure's seismic fortification and the convenience of construction, the design suggests steel fabric and cement mortar to reinforce the surface, with the support of some reinforced concrete columns. With the application of certain techniques and proper construction design, the reinforced surface and columns and the original brick setting are combined together as a composite masonry structure. The reinforced mortar surface and the cement columns make the looping function upon the loose brickwork. When earthquake happens, this construction not only absorbs the seismic shear, but also effectively constraints transverse deflection, which can help to delay cracks developing in the wall and to increase the ductility of the building.

The reinforced steel fabric and mortar surface on the interior and exterior wall is $40 \mathrm{~mm}$ thick; the columns are set at the connecting point of the exterior and the interior wall, with the ductility of cross section $240 \mathrm{~mm}^{*} 180 \mathrm{~mm}$; the exterior wall corner is reinforced by L-shape angle column with both sides $600 \mathrm{~mm}$ long and $150 \mathrm{~mm}$ thick. The reinforce positions in one unit are set at A-1, A-2, A-4, A-5, A-6, C-1, C-3, C-4, C-6, C-7. The longitudinal steel bar in the reinforced column is 4ø16; and in the angle part 2Ф12; both are double laid. For the purpose of increasing the shearing capability of the additional columns, the stirrups are required to be $\Phi 6 @ 150$; density is increased at the range of $500 \mathrm{~mm}$ to the upper and the below floor, with intervals of $100 \mathrm{~mm}$. Both the two reinforced measures are well-developed in construction and technology, which will not be discussed in detail.

The seismic performance index $\beta_{\mathrm{s}}$ can be calculated in the formula $\beta_{S}=\eta \varphi_{1} \varphi_{2} \beta_{0} . \eta$ is reinforcement enhanced modulus, $\beta_{0}$ is reinforcement enhanced modulus of the original wall, calculated according to the technical specifica-

Table 1. Seismic Calculation Results of Original Building

\begin{tabular}{|c|c|c|c|c|c|c|c|}
\hline \multirow{2}{*}{$\frac{\text { Index }}{\text { Wall }}$} & \multirow{2}{*}{$\begin{array}{r}\text { oor } \\
\end{array}$} & \multicolumn{6}{|c|}{ Seismic Resistance Index(Resisting Power /Effect) } \\
\hline & & \multirow{2}{*}{$\frac{\mathbf{1}^{\text {st }} \text { Floor }}{0.99}$} & \multirow{2}{*}{$\frac{2^{\text {nd }} \text { Floor }}{0.98}$} & \multirow{2}{*}{$\frac{\mathbf{3}^{\text {rd }} \text { Floor }}{1.02}$} & \multirow{2}{*}{$\frac{4^{\text {th }} \text { Floor }}{1.16}$} & \multirow{2}{*}{$\frac{\mathbf{5}^{\text {th }} \text { Floor }}{1.51}$} & \multirow{2}{*}{$\frac{6^{\text {th }} \text { Floor }}{2.93}$} \\
\hline \multirow{10}{*}{ Exterior Longitudinal Wall } & A-1 & & & & & & \\
\hline & A-2 & 0.57 & 0.58 & 0.60 & 0.68 & 0.88 & 1.70 \\
\hline & A-4 & 1.78 & 1.82 & 1.55 & 2.86 & 3.03 & 6.13 \\
\hline & A-5 & 0.61 & 0.61 & 0.64 & 0.72 & 0.94 & 1.81 \\
\hline & A-6 & 0.87 & 0.89 & 0.95 & 1.11 & 1.50 & 3.04 \\
\hline & C-1 & 0.73 & 0.90 & 0.95 & 1.08 & 1.43 & 2.91 \\
\hline & $\mathrm{C}-3$ & 1.17 & 0.82 & 0.88 & 1.02 & 1.38 & 2.80 \\
\hline & C-4 & 1.05 & 0.78 & 0.83 & 0.97 & 1.31 & 2.65 \\
\hline & $\mathrm{C}-5$ & 1.39 & 1.74 & 1.80 & 1.99 & 2.51 & 4.63 \\
\hline & C-6 & 0.75 & 0.96 & 1.02 & 1.19 & 1.59 & 3.23 \\
\hline \multirow{3}{*}{ Interior Longitudinal Wall } & B-1 & 0.67 & 0.67 & 0.7 & 0.80 & 1.05 & 2.06 \\
\hline & B-3 & 0.88 & 0.90 & 0.96 & 1.11 & 1.50 & 3.05 \\
\hline & B-6 & 0.92 & 0.94 & 1.01 & 1.18 & 1.60 & 3.259 \\
\hline \multirow{2}{*}{ Gable wall } & $1-\mathrm{A}$ & 0.87 & 0.83 & 0.86 & 0.98 & 1.26 & 2.44 \\
\hline & $1-B$ & 0.81 & 0.81 & 0.85 & 0.96 & 1.27 & 2.44 \\
\hline
\end{tabular}


tion for seismic strengthening of buildings JGJ116-2009; $\varphi_{1}$ is system influence modulus and $\varphi_{2}$ is part influence modulus after enhanced. Those modului are calculated according to the state after enhanced. The seismic performance index $\beta_{\mathrm{s}}$ after reinforcement is shown as follows in Table 2, the seismic calculation results of the building after reinforcment is shown as follows in Table $\mathbf{3}$.

\section{PROPOSAL FOR SEISMIC WEAK POINTS}

Reinforcement on the short walls as below. The bearing capability of the short walls actually satisfies the requirement according to the calculation according to equivalent base shear method, but designers should not neglect the lateral sway phenomenon of masonry structure when earthquake happens. Those sway will lead to the decrease of short walls' torsional rigidity and compressive strength, so that the whole structure will be destroyed and collapse will happen. In this example, both the exterior and interior longitudinal walls have some short walls without the constraint of cross wall to support. The exterior wall is $370 \mathrm{~mm} * 480 \mathrm{~mm}$; the interior wall is $240 \mathrm{~mm}^{*} 480 \mathrm{~mm}$. The size of their section is far smaller than the required limiting value. So it is quite neces-

Table 2. Seismic Reinforcement Index $\boldsymbol{\beta}_{\mathrm{s}}$

\begin{tabular}{|c|c|c|c|c|c|c|c|c|c|c|c|c|c|}
\hline \multirow{2}{*}{$\frac{\text { Index }}{\text { Wall }}$} & \multirow{2}{*}{ loor } & \multicolumn{2}{|c|}{$1^{\text {st }}$ Floor } & \multicolumn{2}{|c|}{$2^{\text {nd }}$ Floor } & \multicolumn{2}{|c|}{$3^{\text {rd }}$ Floor } & \multicolumn{2}{|c|}{$4^{\text {th }}$ Floor } & \multicolumn{2}{|c|}{$5^{\text {th }}$ Floor } & \multicolumn{2}{|c|}{$6^{\text {th }}$ Floor } \\
\hline & & Md1 & Md2 & Md1 & Md2 & Md1 & Md2 & Md1 & Md2 & Md1 & Md2 & Md1 & Md2 \\
\hline \multirow{9}{*}{ Exterior Longitudinal wall } & A-1 & 1.287 & - & 1.326 & - & 1.274 & - & 1.308 & - & 1.936 & - & 3.800 & - \\
\hline & A-2 & 0.754 & 1.620 & 0.780 & 1.599 & 0.754 & 1.540 & 0.884 & 1.335 & 1.144 & 1.730 & 2.210 & - \\
\hline & A-4 & 0.793 & 1.700 & 0.832 & 1.700 & 0.806 & 1.650 & 0.949 & 1.430 & 1.222 & 1.850 & 2.340 & - \\
\hline & A-5 & 1.131 & - & 1.235 & - & 1.157 & - & 1.443 & - & 1.950 & - & 3.950 & - \\
\hline & A-6 & 0.949 & 2.040 & 1.170 & 2.390 & 1.235 & 2.530 & 1.404 & 2.120 & 1.859 & - & 3.650 & - \\
\hline & $\mathrm{C}-1$ & 1.521 & - & 1.066 & 2.180 & 1.144 & 2.340 & 1.326 & - & 1.794 & - & 3.640 & - \\
\hline & $\mathrm{C}-3$ & 1.378 & - & 1.014 & 2.080 & 1.079 & 2.210 & 1.261 & 1.900 & 1.703 & - & 3.440 & - \\
\hline & C-4 & 0.975 & 2.090 & 1.248 & - & 1.326 & - & 1.547 & - & 2.028 & - & 4.200 & - \\
\hline & $\mathrm{C}-5$ & 1.014 & - & 1.261 & - & 1.300 & - & 1.495 & - & 1.950 & - & 3.790 & - \\
\hline \multirow{3}{*}{ Interior Longitudinal wall } & C-6 & - & 1.440 & - & 1.440 & - & 1.435 & - & 1.640 & - & 2.150 & - & 2.670 \\
\hline & B-3 & - & 1.320 & - & 1.320 & - & 1.440 & - & 1.680 & - & 2.260 & - & 4.570 \\
\hline & B-6 & - & 1.978 & - & 2.040 & - & 2.070 & - & 1.780 & - & - & - & - \\
\hline
\end{tabular}

MD1: Method1_-Additional column.

MD2: Method2_ _ Steel fabric and mortar surface.

Table 3. Seismic Calculation Results of the Building after Reinforcement

\begin{tabular}{|c|c|c|c|c|c|c|c|}
\hline \multirow{2}{*}{\multicolumn{2}{|c|}{$\frac{\text { Index }}{\text { Wall }}$}} & \multicolumn{6}{|c|}{ Seismic Resistance Index(Resisting Power /Effect) } \\
\hline & & \multirow{2}{*}{$\begin{array}{c}\mathbf{1}^{\text {st }} \text { Floor } \\
1.29\end{array}$} & \multirow{2}{*}{$\begin{array}{c}\mathbf{2}^{\text {nd }} \text { Floor } \\
1.32\end{array}$} & \multirow{2}{*}{$\begin{array}{c}\mathbf{3}^{\text {rd }} \text { Floor } \\
1.27\end{array}$} & \multirow{2}{*}{$\begin{array}{c}\mathbf{4}^{\text {th }} \text { Floor } \\
1.31\end{array}$} & \multirow{2}{*}{$\begin{array}{c}\mathbf{5}^{\text {th }} \text { Floor } \\
1.94\end{array}$} & \multirow{2}{*}{$\frac{\mathbf{6}^{\text {th }} \text { Floor }}{3.92}$} \\
\hline \multirow{10}{*}{ Exterior Longitudinal Wall } & A-1 & & & & & & \\
\hline & A-2 & 1.64 & 1.59 & 1.54 & 1.33 & 1.72 & 2.29 \\
\hline & A-4 & 1.82 & 1.86 & 2.00 & 2.33 & 3.15 & 6.34 \\
\hline & A-5 & 1.70 & 1.70 & 1.65 & 1.43 & 1.85 & 2.41 \\
\hline & A-6 & 1.13 & 1.32 & 1.15 & 1.44 & 1.95 & 4.10 \\
\hline & C-1 & 1.00 & 1.53 & 1.64 & 1.42 & 2.40 & 4.67 \\
\hline & $\mathrm{C}-3$ & 1.39 & 1.08 & 1.16 & 1.34 & 1.80 & 3.60 \\
\hline & $\mathrm{C}-4$ & 1.63 & 1.24 & 1.79 & 1.54 & 2.08 & 4.17 \\
\hline & C-5 & 1.64 & 2.34 & 2.54 & 2.77 & 3.77 & 7.64 \\
\hline & C-6 & 1.00 & 1.58 & 1.76 & 2.00 & 2.69 & 5.36 \\
\hline \multirow{3}{*}{ Interior Longitudinal Wall } & B-1 & 1.52 & 1.52 & 1.59 & 1.54 & 1.50 & 4.36 \\
\hline & B-3 & 1.01 & 1.03 & 1.11 & 1.29 & 1.73 & 5.20 \\
\hline & B-6 & 1.03 & 1.06 & 1.14 & 1.33 & 1.79 & 3.61 \\
\hline \multirow{2}{*}{ Gable wall } & $1-\mathrm{A}$ & 1.00 & 1.14 & 1.25 & 1.07 & 1.41 & 2.76 \\
\hline & $1-B$ & 2.04 & 2.07 & 2.21 & 2.57 & 3.45 & 6.90 \\
\hline
\end{tabular}




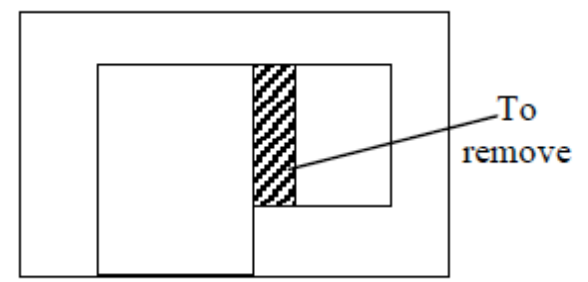

Fig. (2). a) Original local elevation. b) Reinforcement measures.

sary to reinforce the short walls in order to ensure the safety of the massive structure. But the specific method to reinforce should be different according to different position of those short walls. As to the short walls on the interior longitudinal wall, the cabinet door in it is expected to be blocked. As to the short walls on the exterior wall, two proposals are suggested: 1. to add additional reinforced concrete columns. But this method reduces the hole area and may affect the application; 2. to remove the short walls and add side pillars on the big hole in order to increase the rigidity of the window wall. Comparing the two proposals, the second one is suggested, as it completely deletes the safety potentials. The specific method is shown as Fig. (2a and $\mathbf{2 b}$ ).

Reinforcement on the staircase as below. The space rigidity of stair hall affects the stability of massive structure. When earthquake happens, the staircase is normally the first part to be destroyed, so its reinforcement should get much attention. Reinforcement to the staircase should not change the architectural space and the stress bearing approach of the slab staircase. Therefore, to add constructional columns on local parts helps to increase the bearing capability and rigidity of the load-bearing cross wall. As in Fig. (3), the proposal is expected to increases not only the local stress bearing capability of the wall under the landing beam, but also the rigidity and stability of the cross wall.

Reinforcement to the other parts as below. Corner is the intersection of vertical wall and cross wall, the stress is in an extremely complex state under seismic action, the fracture pattern is diversified. To increase the bearing capability of the corners, the constructional columns at the four corners of a building could be enlarged. Because more seismic shear are distributed to the gable wall for its high rigidity, damage of the gable is serious in earthquake. The key to reinforce the gable wall is to strengthen the masonry structure's ductility, which is to add columns at the connecting part of the gable wall and the longitudinal walls, in addition to steel fabric and cement mortar surface.

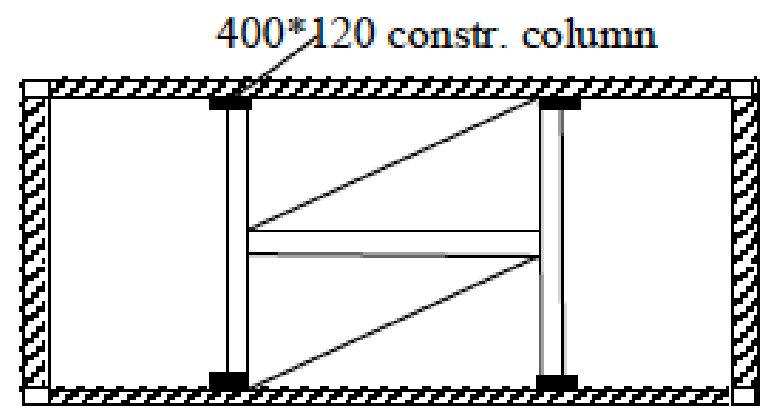

Fig. (3). Reinforcement to the stair hall.

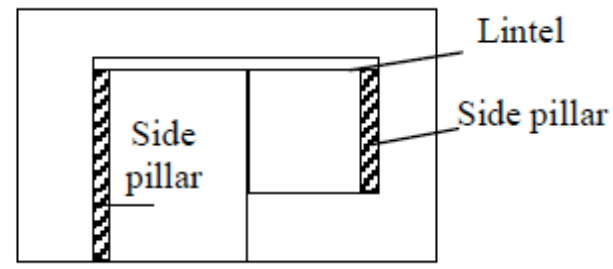

Compared with other layers, the index of top floor was high in the analysis of earthquake resistant. One of the main reasons is that the earthquake-proof checking calculation methods we used is equivalent base shear method, according to this method, because the shear force distributed to the top layers is smaller, so the earthquake-resisting capacity and calculated index are higher. But in fact, top layer is the second layer to be destroyed after top layer under the earthquake. Therefore, no matter whether the floors from fifrth to sixth meet the requirements or not, the reinforcement should be also done in order to increase the whole building's stability. And we suggest, the seismic bearing capability index of the top layer should be enlarged in calculation and reinforcement measures should then be taken accordingly.

\section{CONCLUSION}

In the years of shorted economy, engineers put the seismic safety as the secondary consideration, so there were great dangers in many buildings. With economic development, how to strengthen old structure reasonably and economically is the problem which must be solved in design.

Comprehensive evaluation should be laid on the proposed reinforcement project, including the design shortcomings of its structural concept and measures, the recheck of seismic bearing capacity, the investigation on its current situation, the analysis of its durability. The purpose is to enhance the structural integrity, improve the stress state of structural element, and improve the compound seismic capability. The reinforcement scheme should be design in the following respects, structural concept, stress transfer pathway, construction connection, etc. Enough emphasis should be laid on the seismic weak points, such as bottom and top layers, stair halls, corners and short walls. Any overlook on these short parts may cause serious collapse in the earthquake.

Masonry strengthening with tie column is one of the most popular reinforcing methods. By using this method, the bearing capacity of the wall can be improved, and the possibility of the collapse can be reduced when earthquake happens. The steel fabric and cement mortar surface is another common reinforcing method. Because the steel fixed with the wall tightly, the cracking time of the wall delayed and the friability of masonry structure reduced, so the bearing capacity of the brick wall will be improved, anti-lateral force rigidity enhanced and ductility get better.The steel fabric and cement mortar surface and the concrete columns should be used together to effectively increase the seismic bearing capability of local parts, and to increase the plasticity, ductility and integrity of the masonry structure. Practical showed that the technical of the two strength measures are proven in 
technology and beneficial in economy, and are applicable as universal reinforce methods.

\section{REFERENCES}

[1] X. Y. Lin, Investigation on Wenchuan Seismic Damage and Reflection on the Security of Construction Structure(in chinese), Beijing, China: Architecture \& Building Press, 2009.

[2] Industrial Standards of People's Republic of China: Technical Specification for Seismic Strengthening of Building (JGJ 1162009), Beijing, China: Architecture \& Building Press, 2009.

[3] W. Yayong, "Lessons learn from building damages in the wenchuan earthquake seismic concept design of buildings", Journal of Building Structures, vol. 29, pp. 20-25, 2008.
$[4]$

W. Yayong, "Lessons learnt from building damages in the wenchuan earthquake three earthquake perform objectives and basic requirements for seismic design of buildings", Journal of Building Structures, vol. 29, pp. 26-33, 2008.

[5] L. Bi-Xiong, "Wenchuan earthquake field reconnaissance and analysis on multi-story masonry structure buildings", Journal of Sichuan University (Engineering Science Edition), vol. 41, pp. 19-25, 2009.

[6] L. Bi-Xiong, "Characteristic analysis of performance and damage of buildings in wenchuan earthquake and considerations in a seismic design of buildings", Journal of Disaster Prevention and Mitigation Engineering, vol. 29, pp. 224-230, 2009.

[7] F. Yuan, L. Yifeng, X. Kejian, Experience the Wenchuan Earthquake Structure Engineers' Point and View (in chinese), Beijing, China: Architecture \& Building Press, 2009.

Received: August 13, 2010

(C) Qi and Huang; Licensee Bentham Open.

This is an open access article licensed under the terms of the Creative Commons Attribution Non-Commercial License (http://creativecommons.org/licenses/by-nc/3.0/) which permits unrestricted, non-commercial use, distribution and reproduction in any medium, provided the work is properly cited. 